\title{
Biographical Sketch
}

\section{Paul M. Grammont, MD (1940)}

\author{
Pascal Boileau MD
}

Published online: 20 July 2011

(C) The Association of Bone and Joint Surgeons (B) 2011

\begin{abstract}
This biographical sketch on Paul M. Grammont corresponds to the historic text, The Classic: Delta Shoulder Prosthesis for Rotator Cuff Rupture (1993), available at DOI 10.1007/s11999-011-1960-5.
\end{abstract}

Paul Grammont was born on April 1940 in Salins-lesBains, in the northeastern part of France. His father was a teacher and his mother, who chose to raise the children, was trained as a physicist. During his primary and secondary school years, he lived in various cities as his father taught in different schools. After graduation from secondary school, he began medical studies in Lyon. Very quickly he became interested in surgery, and more specifically in orthopaedic surgery. He first became the fellow and then assistant of Professor Albert Trillat, head of the orthopaedic department in Lyon that was particularly well-known for knee and shoulder surgery. He did his military service overseas, in French Guiana where he had the opportunity to operate on many difficult cases. Encouraged by Albert Trillat, he became a Professor of Orthopaedic Surgery and Traumatology in 1974 at the age of 34 . He then moved to Dijon in eastern France, where he became the Chairman of the Orthopaedic Department of the University Hospital.

While he had few laboratory resources, he was a skilled handyman and began many of his biomechanical experiments on the knee and the shoulder in his own garage before having the opportunity to work in the anatomical and biomechanical labs in the Medical University of Dijon.

P. Boileau $(\square)$

Department of Orthopaedic Surgery \& Sports Traumatology,

Hôpital de L'Archet-University of Nice-Sophia-Antipolis, 151,

Route de St Antoine de Ginestière, 06202 Nice, France

e-mail: boileau.p@chu-nice.fr
Fig. 1 Dr. Paul Grammont is shown in 2011 (Photographs courtesy of Dr. Grammont).

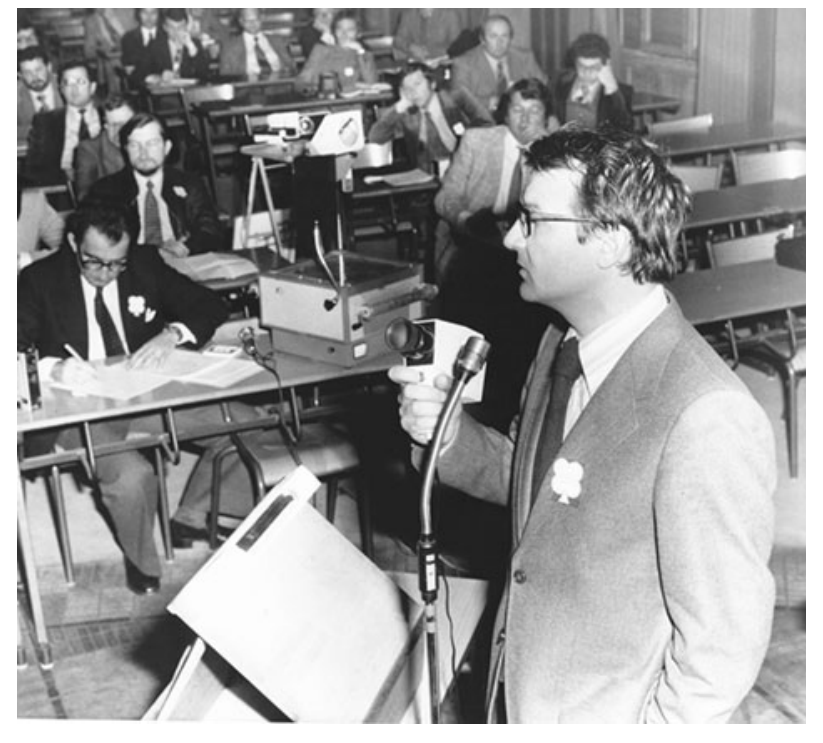

Fig. 2 Dr. Paul Grammont is shown circa 1970 (Photographs courtesy of Dr. Grammont).

Grammont was creative: besides developing the reverse shoulder prosthesis [2,3], he also developed an early patellofemoral prosthesis [6] and one of the first nails with a self-advancing mechanism designed to lengthen 
long bones like the tibia and the femur (Albizia nail) [4]. In 1997, at 57-years-old and in the prime of his career, he had a stroke with right hemiplegia and aphasia. Despite residual deficits, he remains active with carpentry and plumbing in his home, and began a second career as a painter using his left hand. He travels with his wife, Françoise. His successors in Dijon have stayed faithful to his teachings. He currently lives in Lyon.

In 1985, Grammont designed a reverse prosthesis for arthritic shoulders with severe destruction of the cuff, in which standard anatomic prostheses could not solve the problem of restoring both joint stability and mobility. He published his first paper on the reverse prosthesis in the French literature in 1987 [2]. Six years later, in 1993, he summarized the results of his biomechanical studies in English language [3]. The concept of the reverse prosthesis developed by Grammont was a major step forward in the field of shoulder arthroplasty [1]. Previous constrained prostheses (ball and socket or reverse ball and socket designs) all failed because their center of rotation remained lateral to the scapula, which limited motion and produced excessive torque on the prosthesis-bone interface of the glenoid component, leading to early loosening. The reverse shoulder prosthesis designed by Grammont, unlike any previous reverse ball and socket design [5], introduced two major innovations which led to its success: (1) a large metal hemisphere with no neck on the glenoid side, and (2) a small polyethylene cup (covering less than half of the hemisphere), oriented with a nonanatomic inclination of $155^{\circ}$, on the humeral side. This original and totally new design provided a fixed and medialized center of rotation, minimizing torque on the glenoid component, and aided the recruitment of more of the anterior and posterior deltoid to act as abductors. Furthermore, the humerus was lowered in relation to the acromion, increasing the tension of the deltoid fibers. This retensioning of the deltoid, together with the improved lever-arm for the abduction of the anterior and posterior deltoid, allowed the deltoid to compensate for the absent or deficient rotator cuff muscles.
In fact, Grammont's reverse prosthesis imposed a new biomechanical environment for the deltoid muscle. The first generation of the Grammont reverse prosthesis had a large sphere all-cemented on the glenoid side and an allpolyethylene flute on the humeral side. The second generation (Delta reverse prosthesis, DePuy Inc., Warsaw, IN) has been used in France since 1997 and gained increasing popularity throughout Europe. Despite the encouraging early results in Europe, FDA approval for the Delta III prosthesis was not acquired until 2003 in the United States.

The Grammont reverse prosthesis offers a new surgical option in several situations where the rotator cuff and/or the proximal humerus are destroyed or absent, and where previously only limited options were available. Such indications include shoulder pseudo-paralysis due to a massive and irreparable cuff tear with or without osteoarthritis, severe fracture sequelae, failed prosthesis, and tumor surgery.

In this month's issue, we publish a number of papers regarding virtually all aspects of the reverse shoulder arthroplasty and celebrate the contributions of the pioneer, Dr. Paul Grammont.

\section{References}

1. Boileau P, Watkinson DJ, Hatzidakis AM, Balg F. Grammont reverse prosthesis: design, rationale, and biomechanics. $J$ Shoulder Elbow Surg. 2005;14:147S-161S.

2. Grammont PM, Trouilloud P, Laffey JP, Deries X. [In French] Etude et réalisationd'une nouvelle prothèsed'épaule. Rhumatologie. 1987;39:17-22.

3. Grammont PM, Baulot E. Delta shoulder prosthesis for rotator cuff rupture. Orthopedics. 1993;16:65-68.

4. Guichet JM, Grammont PM, Trouilloud P. A nail for progressive lengthening. An animal experiment with a 2-year follow-up. Chirurgie. 1992;118:405-410.

5. Kessel L, Bayley I. Prosthetic replacement of shoulder joint: preliminary communication. J R Soc Med. 1979;72:748-752.

6. Renard JF, Grammont P. [In French] La prothèse autocentrique de rotule: technique et résultats après 7 ans de recul. Rhumatologie. 1989;41:241-245. 